\title{
DETERMINANT FAKTOR KEBERHASILAN TOILET TRAINING PADA ANAK TODDLER DI RW O02 PERUMAHAN SINAR PAMULANG, TANGERANG SELATAN
}

\author{
Rita Dwi Pratiwi
}

STIKes Widya Dharma Husada Tangerang , Jalan Pajajaran No. 1 Pamulang Tangerang Selatan Banten, 15417

\begin{tabular}{|c|c|}
\hline ARTICLE INFORMATION & $\begin{array}{llllllll} & B & S & T & R & A & C & T\end{array}$ \\
\hline $\begin{array}{l}\text { Rita Dwi Pratiwi } \\
\text { Corresponding } \\
\text { E-mail: ritadwipratiwi@wdh.ac.id }\end{array}$ & \multirow{2}{*}{$\begin{array}{l}\text { Toilet training is an attempt to train children to be able to control bowel } \\
\text { movement (BAB) or urinate (BAK). Toilet training can be done in the child's } \\
\text { independence phase, which usually begins at the age of } 18 \text {-36 months. The } \\
\text { objective of this research was to recognize whether there is any correlation } \\
\text { between the level of knowledge of mothers just given counseling, on her } \\
\text { attitude in the implementation of the toilet training and keep participating } \\
\text { actively in toilet training on all children aged } 18 \text {-36 months in } 002 \text { Hamlet, } \\
\text { the Sinar Pamulang Housing Regency, South Tangerang. This study used a } \\
\text { quantitative method. It used children to commit an analytic design with the } \\
\text { cross-sectional approach, the number of the sample was } 61 \text { significant } \\
\text { proportion of respondents, with a purposive sampling method, and used a } \\
\text { questionnaire to prove data collection. The result of this research obtained } \\
\text { there was a correlation knowledge of mothers with their attitude about toilet } \\
\text { training ( } p \text { value 0,000), knowledge of mothers for the implementation of the } \\
\text { toilet training ( } p \text { value 0,000), knowledge of mothers for the success of toilet } \\
\text { training ( } p \text { value 0,002), attitudes of the mother with the implementation of } \\
\text { the toilet training ( } p \text { value 0,017), attitudes of the mothers with the success } \\
\text { of toilet training (p value 0,004), consistency of participating actively in the } \\
\text { implementation of the toilet training (p value 0,000). The fit and proper test } \\
\text { of logistic regression showed that the dependent variable for which the most } \\
\text { influence to successful toilet training is the implementation of the mother } \\
\text { toilet training ( } p \text { value 0,011) with a value of up (persons of very = 5,73). } \\
\text { The results of this study can be a consideration for educational institutions, } \\
\text { especially for students in the effort to optimize the growth of children by } \\
\text { disseminating information about mother's knowledge, mother's attitudes, } \\
\text { implementation, and success of toilet training. }\end{array}$} \\
\hline $\begin{array}{l}\text { Keywords: } \\
\text { - The success of toilet training } \\
\text { - Toilet training } \\
\text { - Toddler }\end{array}$ & \\
\hline $\begin{array}{l}\text { Kata Kunci: } \\
\text { - } \quad \text { Keberhasilan toilet training } \\
\text { - } \quad \text { Toilet training } \\
\text { - } \quad \text { Balita }\end{array}$ & $\begin{array}{l}\text { Toilet training adalah usaha untuk melatih anak agar mampu mengontrol } \\
\text { buang air kecil (BAK) atau buang air besar (BAB) yang dapat dilakukan } \\
\text { pada fase kemandirian anak, yaitu dimulai di usia 18-36 bulan. Tujuan } \\
\text { penelitian ini untuk mengetahui ada tidaknya hubungan antara pengetahuan } \\
\text { ibu, sikap ibu dalam pelaksanaan toilet training dengan keberhasilan toilet } \\
\text { training pada anak usia } 18-36 \text { bulan di wilayah RW } 002 \text { Perumahan Sinar } \\
\text { Pamulang Kota Tangerang Selatan. Metode penelitian ini menggunakan } \\
\text { kuantitatif dan desain analitik dengan pendekatan cross sectional dengan } \\
\text { jumlah sampel } 61 \text { responden. Tenik sampling yaitu purposive sampling. } \\
\text { Hasil penelitian ini diperoleh ada hubungan antara pengetahuan ibu dengan } \\
\text { sikap ibu tentang toilet training ( } p \text { value } 0,000) \text {, pengetahuan ibu dengan } \\
\text { pelaksanaan toilet training ( } p \text { value } 0,000) \text {, pengetahuan ibu dengan } \\
\text { keberhasilan toilet training ( } p \text { value } 0,002) \text {, sikap ibu dengan pelaksanaan } \\
\text { toilet training ( } p \text { value } 0,017) \text {, sikap ibu dengan keberhasilan toilet training } \\
\text { ( } p \text { value } 0,004) \text {, pelaksanaan dengan keberhasilan toilet training ( } p \text { value } \\
\text { 0,000). Hasil regresi logistik menunjukkan bahwa variabel yang paling } \\
\text { berpengaruh terhadap keberhasilan toilet training adalah pelaksanaan ibu } \\
\text { toilet training ( } p \text { value } 0,011 \text {; OR=5,73). Penelitian ini dapat dijadikan } \\
\text { bahan pertimbangan bagi institusi pendidikan dalam upaya optimalisasi } \\
\text { tumbuh kembang yang terkait dengan keberhasilan toilet training. }\end{array}$ \\
\hline
\end{tabular}




\section{PENDAHULUAN}

Toilet training adalah usaha melatih anak agar mampu mengontrol buang air kecil (BAK) atau buang air besar (BAB) yang dapat dilakukan pada fase kemandirian anak, yaitu dimulai di usia 18-36 bulan. Melakukan toilet training pada usia yang tidak tepat dapat menimbulkan masalah pada anak yaitu menolak toileting, sembelit, infeksi saluran kemih, disfungsi berkemih dan enuresis (Hooman, 2013 dalam Ginanjar,2017). Usia yang tepat dalam penerapan toilet training yaitu usia 1,5 tahun pada saat anak sudah mulai bisa berjalan dan berbicara. Pada umumnya anak sudah dapat mengontrol BAB dan BAK yaitu pada saat usia 3 tahun (Soetjiningsih, 2012).

Apabila orang tua tidak menerapkan toilet training pada anaknya akan berdampak anak menjadi keras kepala, anak tidak mandiri, dapat membawa kebiasaan mengompol hingga dewasa dan dapat berdampak pada sosial dan kejiwaannya. Toilet training hendaknya diterapkan pada anak sedini mungkin, seperti melatih anak untuk BAK sebelum tidur agar tidak mengompol di malam hari (Hidayat,2010).

Faktor yang bisa mempengaruhi toilet training pada anak meliputi sikap dan tingkat pengetahuan ibu. Sikap merupakan kesiapan untuk bereaksi terhadap objek lingkungan tertentu sebagai suatu penghayatan terhadap objek (Notoatmodjo,2012). Pengetahuan ibu menenai toilet training sangatlah penting karena dapat berpengaruh pada penerapan toilet training. Ibu yang memiliki tingkat pengetahuan yang baik berarti memiliki pemahaman yang baik tentang manfaat dan dampak toilet training (Arifah,2010). Sikap dan pola asuh orang tua yang memarahi anak dan memberi hukuman akan menimbulkan anak tidak nyaman dan dapat menyebabkan kegagalan toilet training (Shofa,2011).

Keberhasilan dalam penerapan toilet training tidak hanya ditentukan dari kemampuan psikologis, fisik dan anak itu sendiri tetapi juga dari bagaimana kesiapan orang tua untuk mengajarkan toilet training secara benar sehingga anak dapat menerapkannya kelak (Waener,2007). Di Indonesia di perkirakan jumlah balita $30 \%$ dari 250 juta jiwa di Indonesia penduduk Indonesia. Menurut survey Kesehatan Rumah Tangga (AKRT) Nasional di perkirakan jumlah balita yang susah mengontol BAB dan BAK di usia sampai prasekolah mencapai 75 juta anak. Fenomena ini dipicu karena banyak hal yaitu pengetahuan ibu yang kurang untuk melatih anak BAK dan BAB, pemakaian popok sekali pakai dan hadirnya saudara baru (Pusparani,2010). Menurut Subagyo (2010) kejadian yang masih buang air 
kecil secara tidak sengaja sekitar $30 \%$ anak berumur 4 tahun, $10 \%$ anak berumur 6 tahun, 3\% berumur 12 tahun dan 1\% berumur 18 tahun. Untuk mengatasi hal ini, pengenalan kamar mandi dan toilet training seharusnya di lakukan orang tua sejak usia dini yaitu umur 16-18 bulan (Intan,2012).

Hasil dari studi pendahuluan yang dilakukan peneliti di wilayah RW 02 Perumahan Sinar Pamulang Kota Tangerang Selatan dengan cara wawancara terdapat $10 \mathrm{ibu}$ yang memiliki anak usia 18-36 bulan. 6 ibu diantaranya tidak menerapkan toilet training karena kurang paham dengan toilet training. Terdapat 2 ibu yang tidak menerapkan toilet training karena alesan bekerja dan anak diasuh oleh pengasuh dan terdapat 2 ibu yang sudah menerapkan toilet training karena alasan harga diapers mahal .

\section{METODE PENELITIAN}

Penelitian ini menggunakan metode kuantitatif dan desain analitik dengan pendekan cross sectional. Populasi dalam penelitian ini adalah ibu yang memiliki anak dengan usia 18-36 bulan di RW 002 Perumahan Sinar Pamulang Kota Tangerang Selatan adalah sebesar 88 orang.

Sampel dalam penelitian ini sebanyak 61 responden dengan menggunakan teknik non probability sampling yaitu purposive sampling. Penelitian ini menggunakan alat ukur berupa kuesioner pengetahuan, sikap, pelaksanaan dan keberhasilan toilet training.

HASIL

Analisis Univariat

Tabel 1. Distribusi Frekuensi Responden Berdasarkan Usia Ibu di Wilayah RW 002 Perumahan Sinar Pamulang Tangerang Selatan

\begin{tabular}{cccc}
\hline No & Usia & Frekuensi & $\begin{array}{c}\text { Percent } \\
(\%)\end{array}$ \\
\hline 1. & $20-30$ & 31 & 50,8 \\
\hline 2. & $31-40$ & 25 & 41,0 \\
\hline 3. & $41-50$ & 5 & 8,2 \\
\hline & Total & 61 & 100 \\
\hline
\end{tabular}

Berdasarkan tabel 1, menunjukkan

bahwa sebagian besar responden usia 2030 tahun yaitu sebanyak 31 responden $(50,8 \%)$, usia 31-40 tahun sebanyak 25 responden $(41,0 \%)$, dan sebagian kecil responden yang usia 41-50 yaitu sebanyak 5 responden $(8,2 \%)$

Tabel 2. Distribusi Frekuensi Responden Berdasarkan Tingkat Pendidikan Ibu di Wilayah RW 002 Perumahan Sinar Pamulang Tangerang Selatan

\begin{tabular}{cccc}
\hline No & Pendidikan & Frekuensi & $\begin{array}{c}\text { Percent } \\
(\%)\end{array}$ \\
\hline 1. & SD & 5 & 8,2 \\
\hline 2. & SMP & 16 & 26,2 \\
\hline 3. & SMA & 32 & 52,5 \\
\hline 4. & Sarjana (S1) & 8 & 13,1 \\
\hline & Total & 61 & 100,0 \\
\hline
\end{tabular}

Berdasarkan tabel 2 menunjukkan bahwa sebagian besar responden dengan 
pendidikan SMA yaitu sebanyak 32 responden (52,5), responden dengan pendidikan SMP sebanyak 16 responden $(26,2 \%)$, responden dengan pendidikan Sarjana (S1) sebanyak 8 responden $(13,1 \%)$ dan sebagian kecil responden dengan pendidikan SD yaitu sebanyak 5 responden $(8,2 \%)$

Tabel 3. Distribusi Frekuensi Responden Berdasarkan Pekerjaan Ibu di Wilayah RW 002 Perumahan Sinar Pamulang Selatan

\begin{tabular}{llll}
\hline No & Pekerjaan & Frekuensi & $\begin{array}{l}\text { Percent } \\
(\%)\end{array}$ \\
\hline 1. & IRT & 49 & 80,3 \\
\hline 2. & Wiraswasta & 11 & 18,0 \\
\hline 3. & Wirausaha & 1 & 1,6 \\
\hline & Total & 61 & 100,0 \\
\hline
\end{tabular}

Berdasarkan tabel 3 menunjukkan bahwa sebagian besar pekerjaan responden adalah IRT yaitu sebanyak 49 responden $(80,3 \%)$, responden dengan pekerjaan wiraswasta sebanyak 11 responden $(18,0 \%)$ dan sebagian kecil adalah responden dengan pekerjaan wirausaha yaitu sebanyak 1 responden $(1,6 \%)$.

Tabel 4. Distribusi Frekuensi

Responden Berdasarkan Status Hubungan Responden di Wilayah RW 002 Perumahan Sinar Pamulang

\begin{tabular}{cccc}
\hline No & Status & Frekuensi & Percent $(\%)$ \\
\hline 1. & $\begin{array}{c}\text { Ibu } \\
\text { Kandung }\end{array}$ & 61 & 100,0 \\
\hline
\end{tabular}

Berdasarkan tabel 4 menunjukkan status hubungan responden keseluruhan adalah ibu kandung yaitu sebanyak 61 responden $(100,0 \%)$.

\section{Analisis Bivariat}

Hubungan antara Pengetahuan Ibu dengan Sikap Ibu tentang Toilet Training

Tabel 5. Hasil uji korelasi Spearman Rank Pengetahuan Ibu dengan Sikap Ibu tentang Toilet Training

\begin{tabular}{ccc}
\hline Nilai Signifikan & $\begin{array}{c}\text { Koefisien } \\
\text { Korelasi }\end{array}$ & Keterangan \\
\hline 0,000 & 0,438 & $\begin{array}{c}\text { Korelasi } \\
\text { signifikan } \\
\text { sedang }\end{array}$ \\
\hline
\end{tabular}

Berdasarkan tabel 5. menunjukkan nilai signifikan sebesar 0,000 yang menunjukkan bahwa korelasi bermakna atau hipotesis nol ditolak yang berarti ada hubungan pengetahuan ibu dengan sikap ibu tentang toilet training pada anak usia 18-36 bulan di wilayah RW 002 Perumahan Sinar Pamulang Tangerang Selatan dan nilai koefisien korelasi sebesar 0,438, yang menunjukkan korelasi dengan kekuatan sedang.

Hubungan antara Pengetahuan Ibu dengan Pelaksanaan Toilet Training

Tabel 6. Hasil uji korelasi Kendall's Tau Pengetahuan Ibu dengan Pelaksanaan Toilet Training.

\begin{tabular}{ccc}
\hline $\begin{array}{c}\text { Nilai } \\
\text { Signifikan }\end{array}$ & $\begin{array}{c}\text { Koefisien } \\
\text { Korelasi }\end{array}$ & Keterangan \\
\hline 0,005 & 0,351 & $\begin{array}{c}\text { Korelasi } \\
\text { signifikan lemah }\end{array}$ \\
\hline
\end{tabular}


Berdasarkan tabel 6 menunjukkan nilai signifikan sebesar 0,005 yang menunjukkan bahwa korelasi bermakna (Ha diterima) yang artinya terdapat hubungan antara pengetahuan ibu dengan pelaksanaan tentang toilet training pada anak usia 18-36 bulan di wilayah RW 002 Perumahan Sinar Pamulang Tangerang Selatan dengan mengunakan analisa statistik kendall's tau menunjukkan bahwa nilai koefisien korelasi sebesar 0,351 yang artinya memiliki kekuatan korelasi sedang.

Hubungan antara Pengetahuan Ibu dengan Keberhasilan Toilet Training

Tabel 7. Hasil uji korelasi Kendall's Tau Pengetahuan Ibu dengan Keberhasilan Toilet Training

\begin{tabular}{ccc}
\hline $\begin{array}{c}\text { Nilai } \\
\text { Signifikan }\end{array}$ & $\begin{array}{c}\text { Koefisien } \\
\text { Korelasi }\end{array}$ & Keterangan \\
\hline 0,002 & 0,392 & $\begin{array}{c}\text { Korelasi } \\
\text { signifikan lemah }\end{array}$ \\
\hline
\end{tabular}

Berdasarkan tabel 7 diatas menunjukkan nilai signifikan sebesar 0,002 yang menunjukkan bahwa korelasi bermakna atau hipotesis nol ditolak yang berarti ada hubungan pengetahuan ibu dengan keberhasilan toilet training pada anak usia 18-36 bulan di wilayah RW 002 Perumahan Sinar Pamulang Tangerang Selatan, dan menggunakan uji analisa kendall's tau menunjukkan bahwa nilai koefisien korelasi sebesar 0,392 yang berarti dengan kekuatan lemah.
Hubungan antara Sikap Ibu dengan Pelaksanaan Toilet Training

Tabel 8. Hasil uji korelasi Kendall's Tau Sikap Ibu dengan Pelaksanaan Toilet Training

\begin{tabular}{ccc}
\hline $\begin{array}{c}\text { Nilai } \\
\text { Signifikan }\end{array}$ & $\begin{array}{c}\text { Koefisien } \\
\text { Korelasi }\end{array}$ & Keterangan \\
\hline 0,017 & 0,292 & $\begin{array}{c}\text { Korelasi signifikan } \\
\text { sangat lemah }\end{array}$ \\
\hline
\end{tabular}

Berdasarkan tabel 8 diatas menunjukkan nilai signifikan sebesar 0,017 yang menunjukkan bahwa korelasi bermakna (Ha diterima) yang berarti ada hubungan sikap ibu dengan pelaksanaan toilet training pada anak usia 18-36 bulan di wilayah RW 002 Perumahan Sinar Pamulang Tangerang Selatan, dan menggunakan analisa kendall's tau menunjukkan bahwa nilai koefisien korelasi sebesar 0,292 yang berarti korelasi kekuatan sangat lemah.

Hubungan antara Sikap Ibu dengan Keberhasilan Toilet Training

Tabel 9. Hasil Uji Korelasi Kendall's Tau Sikap Ibu dengan Keberhasilan Toilet Training

\begin{tabular}{ccc}
\hline $\begin{array}{c}\text { Nilai } \\
\text { Signifikan }\end{array}$ & $\begin{array}{c}\text { Koefisien } \\
\text { Korelasi }\end{array}$ & Keterangan \\
\hline 0,004 & 0,352 & $\begin{array}{c}\text { Korelasi } \\
\text { signifikan lemah }\end{array}$ \\
\hline
\end{tabular}

Berdasarkan tabel 9 di atas menunjukkan nilai signifikan sebesar 0,004 yang menunjukkan bahwa korelasi bermakna atau hipotesis nol ditolak yang 
berarti ada hubungan sikap ibu dengan keberhasilan toilet training pada anak usia 18-36 bulan di wilayah RW 002 Perumahan Sinar Pamulang Tangerang Selatan dengan menggunakan analisa kendall's tau menunjukkan bahwa nilai koefisien korelasi sebesar 0,352 yang berarti menunjukkan nilai korelasi dengan kekuatan lemah.

\section{Hubungan antara Pelaksanaan dengan} Keberhasilan Toilet Training

Tabel 10. Hasil uji korelasi Koefisien Kontingensi Pelaksanaan dengan Keberhasilan Toilet Training

\begin{tabular}{ccc}
\hline $\begin{array}{c}\text { Nilai } \\
\text { Signifikan }\end{array}$ & $\begin{array}{c}\text { Koefisien } \\
\text { Korelasi }\end{array}$ & Keterangan \\
\hline 0,000 & 0,434 & $\begin{array}{c}\text { Korelasi } \\
\text { signifikan sedang }\end{array}$ \\
\hline
\end{tabular}

Berdasarkan tabel 10 menunjukkan nilai signifikan sebesar 0,000 yang menunjukkan bahwa korelasi bermakna atau hipotesis nol ditolak yang berarti ada hubungan pelaksanaan dengan keberhasilan toilet training pada anak usia 18-36 bulan di wilayah RW 002 Perumahan Sinar Pamulang Tangerang Selatan .

Analisis menggunakan analisa kendall's tau nilai koefisien korelasi sebesar 0,434 yang berarti menunjukkan nilai korelasi dengan kekuatan sedang.

\section{Analisis Multivariat}

Hubungan antara Pengetahuan Ibu, Sikap Ibu dan Pelaksanaan Toilet Training dengan Keberhasilan Toilet Training

Tabel 11. Hasil uji Regresi Logistik

Pengetahuan Ibu, Sikap Ibu dan Pelaksanaan Toilet Training dengan Keberhasilan Toilet Training

\begin{tabular}{cccl}
\hline No & Model & Sig. & OR \\
\hline 1. & Pelaksanaan & 0,011 & 5,733 \\
\hline 2. & Sikap Ibu & 0,109 & 1,967 \\
\hline 3. & Pengetahuan Ibu & 0,185 & 2,101 \\
\hline
\end{tabular}

Berdasarkan tabel 11 dari hasil uji statistik regresi logistik menunjukkan bahwa variabel yang paling berpengaruh terhadap keberhasilan toilet training adalah pelaksanaan ibu toilet training dengan nilai sig 0,011,kekuatan hubungan terbesar dalam penelitian ini berasal dari variabel pelaksanaan toilet training yaitu dengan nilai $(\mathrm{OR}=5,73)$ dan dengan sig 0,011 .

\section{PEMBAHASAN}

Gambaran Pengetahuan Ibu Tentang Toilet training

Pengetahuan ibu tentang toilet training menunjukkan bahwa sebagian besar pengetahuan responden baik yaitu 31 responden $(50,8 \%)$. Tingkat pengetahuan responden tentang toilet training dipengaruhi oleh beberapa faktor antara lain $\mathrm{h}$ tingkat pendidikan dan adanya informasi dari petugas kesehatan (Arifah, 
2010). Sebagian besar pengetahuan ibu baik berpendidikan SMA yaitu sebanyak 32 responden (52,46\%). Menurut Departemen Pendidikan (2000), seseorang yang telah menempuh pendidikan minimal 9 tahun sudah termasuk dalam kategori baik.

\section{Gambaran Sikap Ibu Tentang Toilet training}

Sikap ibu menunjukkan bahwa sebagian besar memiliki sikap baik tentang toilet training yaitu sebanyak 29 responden $(47,5 \%)$. Sikap positif yaitu kecenderungan untuk mendekati dan mengharapkan objek tertentu. Sikap negatif adalah kecenderungan untuk menghindari dan tidak menyukai objek tertentu (Mujahidatul, 2014). Menurut Azwar (2013), salah satu faktor yang mempengaruhi sikap yaitu pengaruh orang lain yang dianggap penting. Hal ini menunjukkan bahwa ibu sangat berpengaruh penting bagi anak sebagi motivasi untuk melakukan toilet training.

Sikap dan pola asuh orang tua yang memarahi anak dan memberi hukuman akan menimbulkan anak tidak nyaman dan dapat menyebabkan kegagalan toilet training(Shofa,2011). Gambaran sikap ibu yang baik dalam toilet training dapat digambarkan seperti memberikan pujian pada anak ketika anak berhasil melakukan toilet training, tidak memakaikan popok sekali pakai setelah anak memasuki usia 18 bulan, membiasakan anak memulai toilet training mulai dari hal kecil seperti cuci tangan dan kaki, sikat gigi sebelum tidur dan mengawasi anak ketika ke toilet.

\section{Gambaran Pelaksanaan Toilet training}

Pelaksanaan toilet training menunjukkan bahwa sebagian besar responden yang mandiri dalam pelaksanaan toilet training yaitu sebanyak 40 responden $(65,6 \%)$. Menurut Pambudi (2006) Faktor yang mendukung pelaksanaan toilet training adalah komunikasi. Sampaikan pada anak bahwa anak sudah siap untuk mulai belajar toilet training . Komunikasikan semua proses toilet training pada anak seperti membuka dan memakan celana sebelum dan sesudah buang air, jongkok dan lalu bersihkan kelamin agar kelamin tetap bersih.

Salah satu gambaran Pelaksanaan ibu yang membuat anak mandiri adalah selalu melatih anak toilet training dari usia 1 tahun dan memulai melatih toilet training dengan cara teknik lisan mengajarkan anak untuk melatih sesuatu jika ingin BAK dan BAB misalnya "pipis" atau "pup" (Firmansyah,2016).

\section{Gambaran Keberhasilan Toilet training}

Distribusi keberhasilan toilet training menunjukkan bahwa sebagian besar yang berhasil dalam toilet training yaitu sebanyak 42 rsponden $(68,9 \%)$. Hal 
ini sesuai dengan teori Maharani (2011) yang menyatakan dalam mengajarkan toilet training membutuhkan pengertian, waktu dan kesabaran. Hal terpenting yang perlu diingat yaitu ibu tidak dapat memaksa anak untuk menggunakan toilet.

Gambaran anak yang sudah berhasil melakukan toilet training yaitu anak berhasil bangun tidur tanpa mengompol dan anak tidak mengompol selama beberapa jam perhari hari (minimal 3-4 jam. Selain itu anak menggunakan kata “pipis" ketika ingin buang air kecil, anak memberi tahu jika celana/popoknya basah dan kotor, dan anak dapat menyiram toiletnya secara mandiri.

\section{Hubungan antara pengetahuan ibu dengan sikap ibu}

Pengetahuan tentang toilet training yaitu sejauh mana pengetahuan ibu tentang dampak dan keuntungan dari pelatihan toilet training. Tingkat pengetahuan responden tentang toilet training yang baik dipengaruhi oleh beberapa faktor, antara lain tingkat pendidikan, usia dan pengalaman. Ibu yang telah memiliki pengalaman sebelumnya cenderung lebih memahami tentang manfaat dari penatalaksanaan yang dilaksanakan, sehingga ia cenderung memiliki sikap yang lebih baik. Sikap ibu yang baik dalam toilet training ditunjukkan oleh perilaku ibu dalam melatih anak yaitu dengan tidak memarahi ketika anak gagal dalam melakukan toilet training.

Sikap toilet training ibu yang baik dipengaruhi oleh faktor usia dan budaya atau kebiasaan yang ada di masyarakat (Pusparani,2010). Adanya budaya atau kebiasaan menjaga kebersihan dimana salah satunya adalah melakukan kegiatan toilet training di kamar mandi atau toilet merupakan faktir yang mempengaruhi sikap toilet training pada ibu-ibu di wilayah RW 002 Perumahan Sinar Pamulang Tangerang Selatan (Winda,2010).

Hal ini sesuai dengan penelitian sebelumnya yang dilakukan oleh rohadi (2013) yaitu dengan judul hubungan pengetahuan dengan sikap ibu tentang pelaksanaan toilet training pada anak usia todddler di PAUD Desa Semunggih, Kecamatan Rongkop, Kabupaten Gunung Kidul Yogyakarta dengan nilai signifikasi yaitu 0,003menunjukkan bahwa terdapat hubungan yang signifikan antara pengetahuan dengan sikap ibu tentang pelaksanaan toilet training pada anak usia todddler di PAUD Desa Semunggih, Kecamatan Rongkop, Kabupaten Gunung Kidul Yogyakarta.

\section{Hubungan antara pengetahuan dengan pelaksanaan toilet training}

Orang tua harus memiliki pengalaman dan pengetahuan dalam toilet 
training (Kiddo,2011). Pelaksanaan ibu yang baik dapat dilihat dari cara ibu mengajak anak ke kamar mandi sebelum dan sesudah tidur, mengajarkan anak memakai dan melepas celananya sendiri dan selalu mengawasi anak ketika toilet training.Dilihat dari hasil penelitian di wilayah RW 002 Perumahan Sinar Pamulang Tangerang Selatan, responden sebagian besar berpendidikan SMA. Hal tersebut dapat mempengaruhi pengatahuan ibu terhadap pelaksanaan toilet training. Hasil tersebut menunjukkan bahwa semakin ibu paham mengenai toilet training dan paham mengenai cara-cara pelaksanaannya, maka akan dapat melaksanakan toilet training dengan baik dan benar (Arifah,2010).

Melatih anak ke toilet tidak hanya memperlihatkan kesiapa anak namun kesiapan orang tua juga diperlukan, salah satunya kesiapan scara emosional dan pengethauan.Hal ini dapat dikarenakan bahwa ada kecenderungan semakin tinggi tingkat pengetahuan ibu maka semakin tinggi pula kecenderungan mengajarkan toilet training pada anak.

Hal ini sesuai dengan penelitian sebelumnya oleh Fithria (2010), dengan judul hubungan tingkat pengetahuan ibu tentang toilet training dengan pelaksanaan toilet training pada anak usia toddler di Posyandu Hendilem Di Yogyakarta Tahun 2010 yaitu dengan nilai signifikasi 0,000 hal ini menunjukkan terdapat hubungan yang signifikaan antara tingkat pengetahuan ibu tentang toilet training dengan pelaksanaan toilet training dengan pelaksanaan toilet training pada anak usia toddler di Posyandu Hendilem Di Yogyakarta Tahun 2010.

\section{Hubungan antara pengetahuan dengan keberhasilan toilet training}

Pengetahuan ibu yang baik sangat berperan penting bagi keberhasilan toilet training, semakin ibu memiliki pengetahuan yang lebih banyak tentang manfaat dan dampak pada toilet training maka akan berdampak positif terhadap anak dan akan akan lebih mandiri. Sehingga dengan pendidikan ibu yang baik, tingkat keberhasilan toilet training akan semakin besar. Para orang tua khususnya ibu terkadang masih bingung bagaimana dan kapan harus memulai toilet training untuk anaknya. Sebetulnya cukup mudah untuk mengetahui kapan anak sudah dapat dikenalkan toilet training. Keberhasilan toilet training dapat dilihat dari kebiasaan anak yang sudah berhasil tidak mengompol pada saat bangun tidur, anak membuka dan memakai celananya secara mandiri, dan anak akan memberi tahu jika celana atau popoknya basah atau kotor.

Hal ini sesuai dengan hasil penelitian sebelumnyayang dilakukan oleh 
Rusita (2014) dengan judul hubungan pengetahuan dan peran orang tua dengan keberhasilan toilet training pada anak usia toddler dengan nilai signifikasi 0,000 maka terdapat hubungan yang signifikan antara pengetahuan ibu dengan keberhasilan toilet training di PAUD DesA Suwaloh Kecamatan Balen Kabupaten Bojonegoro.

\section{Hubungan antara sikap ibu dengan pelaksanaan toilet training}

Sikap adalah respons tertutup seseorang terhadap suatu stimulus atau objek, baik bersifat intern maupun ekstren. Sikap secara realitas menunjukkan adanya kesesuaian respon terhadap stimulus tertentu. (Notoatmodjo,2008). Stimulus yang sebelumnya diberikan berupa pengetahuan mengenai toilet training, mendorong ibu untuk melakukan praktik. Sikap ibu yang baik dengan selalu mengawasi anak ketika toilet dan membiasakan anak pergi kekamar mandi akan menjadi salah satu faktor yang mempegaruhi keberhasilan anak dalam toilet training.

Penelitian ini sejalan dengan penelitian yang dilakukan oleh Witari (2017) dengan judul pengatahuan dan sikap ibu dalam pelaksanaan toilet training pada anak usia toddler di Posyandu Raflesia Jorong Batang Palupuh dengan nilai siginifikasi 0,014 yang diartikan terdapat hubungan yang signifikan antara pengetahuan ibu dan sikap ibu dalam pelaksanaan toilet training pada anak usia toddler di Posyandu Raflesia Jorong Batangg Palupuh.

\section{Hubungan sikap ibu dengan keberhasilan toilet training}

Tujuan toilet training adalah anak dapat menjaga kebersihan diri, mengajarkan anak untuk dapat memakai celananya kembali serta dapat membentuk kemandirian yang baik dalam melakukan buang air (Wong,2009). Salah satu faktor penunjang keberhasilan perilaku toilet training dipengaruhi oleh kesiapan orang tua berupa dukungan dan peran dari orang tua. Namun, dewasa ini masih banyak seorang ibu yang belum mengerti cara mengajarkan toilet training pada anak (Tukhusnah, 2012). Perilaku yang kurang tepat, mengakibatkan anak dapat cenderung berperilaku keras kepala, tidak percaya diri, dan takut melakukan sesuatu hal. Saat orang tua memberikan aturan yang santai maka anak akan cenderung memiliki kepribadian yang ceroboh, membuat masalah dan kebersihan diri kurang (Wati,2015).

Hal ini sesuai dengan penelitian sebelumnya oleh Batuatas (2012), dengan judul pengaruh peran ibu dengan keberhasilan toilet training pada anak usia toddler di Play Grup Tarbiyatus Shibian 
Mojoanyar Mojokerto yaitu dengan nilai signifikasi 0,004 hal ini menunjukkan terdapat hubungan yang signifikan antara pengaruh peran ibu dengan keberhasilan toilet training pada anak usia toddler di Play Grup Tarbiyatus Shibian Mojoanyar Mojokerto.

\section{Hubungan pelaksanaan toilet training dengan keberhasilan toilet training}

Pelaksanaan toilet training yang baik dan benar, akan sangat berpengaruh terhadap keberhasilan toilet training. Dengan ibu memberikan instruksi pada anak dengan kata kata sebelum dan sesudah BAK dan BAB, kesiapan anak akan semakin matang dalam toilet training. Dan juga ibu bisa memberikan teknik modeling atau sebagai contoh agar anak menirukannya. Dengan ibu membiasakan anak dengan latihan ini, keberhasilan toilet akan semakin tinggi. Dan anak akan membiasakan mengatakan secara verbal bahwa dia ingin BAK dan BAB (Warner,2007).

Penelitian ini sejalan dengan penelitian Rizki (2012) dengan judul hubungan kesiapan anak dengan keberhasilan toilet training pada anak Paud Bungong Seuleupoek Unsyiah Darussalam Banda Aceh dengan nilai signifikasi 0,043 maka terdapat hubungan yang signifikan antara hubungan kesiapan anak dengan keberhasilan toilet training pada Paud Bungong Seuleupoek Unsyiah Banda Aceh.

Hubungan antara pengetahuan ibu, sikap ibu, dan pelaksanaan toilet training dengan keberhasilan toilet training

Faktor yang mempengaruhi keberhasilan toilet training antara lain motivasi orang tua dan kesiapan anak secara fisik, psikologis maupun secara intelektual dan motivasi orang tua itu sendiri dipengaruhi oleh faktor intrinsik dan faktor ekstrinsik (Hidayat,2008). Faktor intristik merupakan dorongan yang berasal dari dalam diri seseorang yaitu berupa pengetahuan, sikap, keadaan mental, dan kematangan usia sedangkan faktor ekstrinsik yaitu berupa sarana, prasana dan lingkungan.

Proses toilet training yang dilakukan oleh orang tua dapat mengalami kegagalan pada anak. Hal ini dapat dikarenakan oleh faktor keluarga terutama ibu dimana kurangnya kepedulian ibu sehingga toilet training ini terabaikan atau pelatihan toilet training yang terlalu dini (Ningsih,2012).

Pelaksanaan dipengaruhi oleh kehendak sedangkan kehendak dipengaruhi oleh sikap .sikpa sendiri dipengaruhi oleh keyakinan akan hasil dari tindakan yang telah lalu. Suatu sikap belum otomatis terwujud dalam suatu tindakan untuk terwujudnya sikap menjadi 
suatu

perpuatan

nyata

(Notoatmodjo,2007).

Pelaksanaan toilet training ibu dipengaruhi oleh sikap, yaitu ibu harus bersikap tegas saat mengajarkan toilet training tidak sedikit orang tua kebingungan, merasa sudah berupaya dengan berbagai tetapi tidak ada perubahan yang berarti. Salah satu penyebab ketiakberhasilan dalam toilet training biasanya tidak lain karena orang tua tidak bersikap inkonsisten.

\section{KESIMPULAN}

Kesimpulan penelitian ini yaitu ada hubungan antara pengetahuan ibu dengan sikap ibu tentang toilet training menunjukkan nilai signifikan 0,000 , ada hubungan antara pengetahuan ibu dengan pelaksanaan toilet training menunjukkan nilai signifikasi 0,000 , ada hubungan antara pengetahuan ibu dengan keberhasilan toilet training menunjukkan nilai signifikasi 0,002 , ada hubungan antara sikap ibu dengan pelaksanaan toilet training menunjukkan nilai signifikasi 0,017, ada hubungan antara sikap ibu dengan keberhasilan toilet training diatas menunjukkan nilai Siginicancy sebesar 0,004, ada hubungan pelaksanaan dengan keberhasilan toilet training menunjukkan nilai Siginicancy sebesar 0,000, dan hasil uji statistik regresi logistik menunjukkan bahwa variabel yang paling berpengaruh terhadap keberhasilan toilet training adalah pelaksanaan ibu toilet training dengan nilai sig 0,011 dengan nilai $(\mathrm{OR}=5,73)$. Hasil penelitian ini dapat dijadikan bahan pertimbangan bagi institusi pendidikan dalam upaya optimalisasi tumbuh kembang yang terkait dengan keberhasilan toilet training

\section{DAFTAR PUSTAKA}

Azhari,Akyas. 2007. Psikologi Umum dan Perkembangan. Jakarta : Teraju

Azwar, Saifuddin. 2013. Sikap Manusia : Teori dan Pengukurannya. Yogyakarta :Liberty.

Hidayat,Aziz Alimul.2013. Metode Penelitian Keperawatan dan tehnik analisa data. Jakarta : Salemba Medika

Anggit Ginanjar.2017. Hubungan Toilet training dengan Kejadian Enuresis Pada Anak Usial-3 Tahun di Desa Jati Kecamatan Binangun Kabupaten Cilacap. Diunduh Pada Tanggal 3 April 2018

Arifah,Siti. 2010. Hubungan Pengetahuan Ibu Tentang Toilet training dengan Perilaku Ibu dalam Melatih Toilet training pada Anak Usia Toddler di Desa Kedokan Sukoharjo. Diunduh 24 Maret 2018

Batuatas. 2012. Pengaruh Peran Ibu Dengan Keberhasilan Toilet training Pada Anak Usia Toddler Di Play Grup Tarbiyyatush Shibiyan Mojoanyar Mojokerto. Diunduh pada tanggal 27 Mei.

Canbulat, N. Yildiz, S. (2009). Current Information On Enuresis. Jurnal Pediatric. 
Elsera,Chori. 2016. Tingkat Pengetahuan Berhubungan dengan Sikap Ibu dalam Toilet training pada Toddler. Diunduh pada tanggal 8 April 2018

Fithria Nurul, 2010, Hubungan Tingkat Pengetahuan Ibu Tentang Toilet training Dengan Pelaksanaan Toilet training Pada Anak Usia Toddler Di Posyandu Hendilen Di Yogyakarta. Diunduh pada tanggal 21 Mei.

Frestina, Yeni. (2012). Hubungan Pengetahuan Ibu Dengan Sikap Ibu Dalam Toilet training Pada Anak Toddler Di Desa Glidogan Kecamatan Klaten Selatan.

Keen,Deb.2007. Toilet training for Children with Autism: The Effects of Developmental and Physical Disabilities.Diunduh Pada Tanggal 30 Maret.

Kiddoo, D. A. Toilet training Children : When To Start And How To Train.

Kusumaningrum,A. dkk (2011). Pengaruh Pendidikan Kesehatan Terhadap Perilaku Orang Tua Dalam Toilet training Toddler. Jurnal Ilmu Kesehatan Masyarakat. Di Unduh tanggal 30 Maret 2018.

Hidayat A.Y. (2012). Hubungan Tingkat Pengetahuan Dengan Praktik Toilet training Pada Ibu Yang Mempunyai Anak Usia Toddler Di Posyandu Flamboyan, Dusun Karangbendo, Banguntapan, Bantul.

Hooman.2013.Toilet training in Iranian children.Iranian Journal of Pediatrics.

Hutomo, Setyo. 2012. Hubungan Tingkat Pengetahuan Dan Sikap Ibu Dengan Praktik Ibu Dalam Menerapkan Toilet training Pada Usia Toddler Di
Kelurahan Jerres Surakarta. Diunduh pada tanggal 21 Mei.

Musfiroh. 2014. Penyuluhan Terhadap Sikap Ibu dalam Memberikan Toilet training Pada Anak. Diunduh pada tanggal 24 maret.

Ningrum. 2016. Keberhasilan Toilet training Pada Anak Usia 2-3 Tahun Di Dusun Telagasi Desa Jabon Kecamatan Mojoantar Kabupaten Mojokerto. Di unduh pada tanggal 24 Mei.

Ningsih 2012. Hubungan Pengetahuan Ibu dan Perilaku Ibu Dala Menerapkan Toilet Trining Dengan Kebiasaan Mengompol Pada Anak Usia Prasekolah Di RW 02 Kelurahan Babakan Kota Tangerang. Diunduh pada tanggal 24 Mei.

Pusparani,Winda (2010). Hubungan Pengetahuan Ibu Tentang Toilet training dengan Perilaku Ibu dalam Melatih Toilet training Pada Anak Usia Toddler di Desa Kadokan Sukoharjo. Diunduh tanggal 27 Maret 2018.

Putri,Anggita (2016). Hubungan Tingkat Pengetahuan Ibu Tentang Toilet training Terhadap Pelaksanaan Toilet training Pada Anak Usia Toddler Di Kelurahan Sewu Surakarta. Di unduh pada tanggal $24 \mathrm{Mei}$

Rahayuningsi Sri Intan,Mula Rizki. 2012. Kesiapan Anak Dan Keberhasilan Toilet training di PAUD dan TK Bungong Seuleupoek Unsyiah Banda Aceh. Diunduh tanggal 27 Maret 2018.

Rohadi, Ihmanudin (2013). Hubungan Pengetahuan Dengan Sikap Ibu Tentang Pelaksanaan Toilet Triining Pada Anak Usia Toddler Di Paud Desa Semugih Kecamatan Rongkop Kabupaten Gunung Kidul Yogyakarta. Diunduh pada tangal 21 Mei. 
Rusita, Ardianti (2014). Hubungan Pengetahuan Ibu Dan Peran Tua Dengan Keberhasilan Toilet training Pada Anak Usia 5 Tahun Di TK Desa Suwaloh Kecamatan Balen Kabupaten Bojonegoro. Diunduh pada tanggal 24 Mei

Shofa Diyak. Umami 2011. Hubungan Pola Asuh Orang Tua dengan Keberhasilan Toilet training Pada Usia Toddler 4-6 Tahun di TK Puspasari I Sidomoyo Godean Slemn D.I Yogyakarta. Diunduh tanggal 24 Maret 2018.

Septiani, Winnie, (2009), Pendekatan Kombinasi Metode AHP dan Netode cut off point pada informasi di PT Indira. Travindo

Soetjiningsih.2012. Perkembangan Anak dan Permasalahannya dalam Buku Ajar I Ilmu Perkembangan Anak dan Remaja. Jakarta : Sagungesto

Sugiyono.2016. Metode Penelitian: Pendekatan Kuantitatif, Kualitatif, dan $R \& D)$. Jakarta

Tirzalola . 2017. Hubungan Tingkat Pengetahuan Ibu Tentang Toilet training Dengan Melatih Toilet training Pada Anak Usia Toddler Di Perumahan Permata Pamulang Kota Tangerang Selatan.

Triningsih,T. (2014). Pengaruh Pendidikan Kesehatan Toilet training Terhadap Tingkat Pengetahuan Ibu Tentang Toilet Tarining Di Paud Tunas Harapan Kutoarjo Purwerejo.

Warner,Penny.2007. Mengajar anak pergi ke toilet. Jakarta: Arcan 